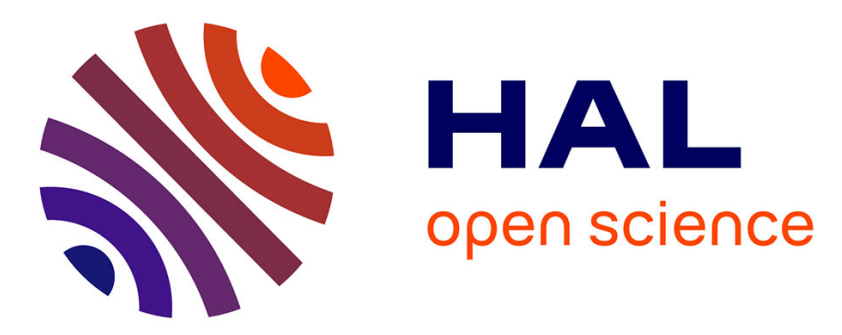

\title{
Recent developments of the two-dimensional technological process simulator OSIRIS
}

\author{
N. Guillemot, G. Pananakakis, P. Chenevier
}

\section{To cite this version:}

N. Guillemot, G. Pananakakis, P. Chenevier. Recent developments of the two-dimensional technological process simulator OSIRIS. Revue de Physique Appliquée, 1987, 22 (7), pp.477-485. 10.1051/rphysap:01987002207047700 . jpa-00245564

\section{HAL Id: jpa-00245564 https://hal.science/jpa-00245564}

Submitted on 1 Jan 1987

HAL is a multi-disciplinary open access archive for the deposit and dissemination of scientific research documents, whether they are published or not. The documents may come from teaching and research institutions in France or abroad, or from public or private research centers.
L'archive ouverte pluridisciplinaire HAL, est destinée au dépôt et à la diffusion de documents scientifiques de niveau recherche, publiés ou non, émanant des établissements d'enseignement et de recherche français ou étrangers, des laboratoires publics ou privés. 
Classification

Physics Abstracts

$05.60-61.70-02.60$

\title{
Recent developments of the two-dimensional technological process simulator OSIRIS
}

\author{
N. Guillemot, G. Pananakakis and P. Chenevier \\ I.N.P.G.-E.N.S.E.R.G., Laboratoire de Physique des Composants à Semiconducteurs, Unité Associée au \\ CNRS $n^{\circ}$ 840, 23, avenue des Martyrs, 38031 Grenoble Cedex, France
}

(Reçu le 27 novembre 1986, révisé le 10 mars 1987, accepté le 13 mars 1987)

\begin{abstract}
Résumé. - La simulation numérique des processus technologiques est très importante pour la fabrication des circuits intégrés. Dans cet article, les auteurs présentent une version plus complète du simulateur bidimensionnel OSIRIS, prenant en compte la diffusion simultanée de deux impuretés. Les modèles utilisés pour l'implantation ionique et la redistribution des dopants sont brièvement rappelés. Un nouveau modèle a été développé pour la croissance de l'oxyde de champ : il permet une très bonne simulation du « bec d'oiseau » obtenu par le procédé SEMIROX. Comme exemple, la réalisation d'un dispositif N-MOS complet est simulée par le programme, qui donne le profil des impuretés et la forme de l'oxyde à la fin du processus.
\end{abstract}

\begin{abstract}
The numerical simulation of technological processes is very important for the fabrication of integrated circuits. In this paper, the authors present a more complete version of the two-dimensional simulator OSIRIS, taking into account the simultaneous diffusion of two impurities. The models used for ionimplantation and redistribution of dopants in silicon are briefly recalled. A new analytical model for oxide growth has been developed which gives very good simulation of the « bird's beak » of SEMIROX structures. Finally, a complete simulation of a N-Channel MOS device is presented, with the redistributed impurity profiles and the oxide layer shape at the end of the process.
\end{abstract}

\section{Introduction.}

The numerical simulation of the technological processes become very important for the fabrication of integrated circuits. Especially for MOS circuits several two-dimensional simulators [1-3] have been proposed in order to take into account the inhomogeneity of the field oxide thickness and the lateral diffusion effects. Similar to the simulators given in $[1,2]$, the authors have developed the program OSIRIS $[4,5]$. It allows the simulation of a complete device fabrication process including the following steps :

- resist deposition and removing

- oxide or nitride deposition and etching

- ion-implantation or predeposition of boron, arsenic, phosphorus and antimony

- redistribution of one or two impurities in an inert or oxidizing ambient

- growth of the gate or field oxide.

In our program the solution of the diffusion equation is performed numerically using a finite difference method. An original and accurate simulation of the «bird's beak » formation in the case of a semi-recessed oxide (SEMIROX process) is presented in this paper. Section 2 briefly describes the modelling of ion-implantation and the resolution of the diffusion equation. The detailed simulation of the field oxide growth is presented in section 3. In the last section, the simulation of a complete $\mathrm{N}$ Channel MOS circuit fabrication process is given.

\section{Ion-implantation and redistribution of impurities.}

In this section the models for ion-implantation and diffusion of impurities are briefly recalled.

2.1 ION-IMPLANTATION. - Ion-implantation and chemical predeposition are the two selective doping techniques used to create localized junctions in a semiconductor : silicon dioxide, polysilicon or resist act as a mask for impurities in silicon. Predeposition can be treated as an impurity diffusion. Therefore, only models used for ion-implantation of boron, 
arsenic, phosphorus and antimony are developed here. The silicon wafer geometry is presented in figure 1.

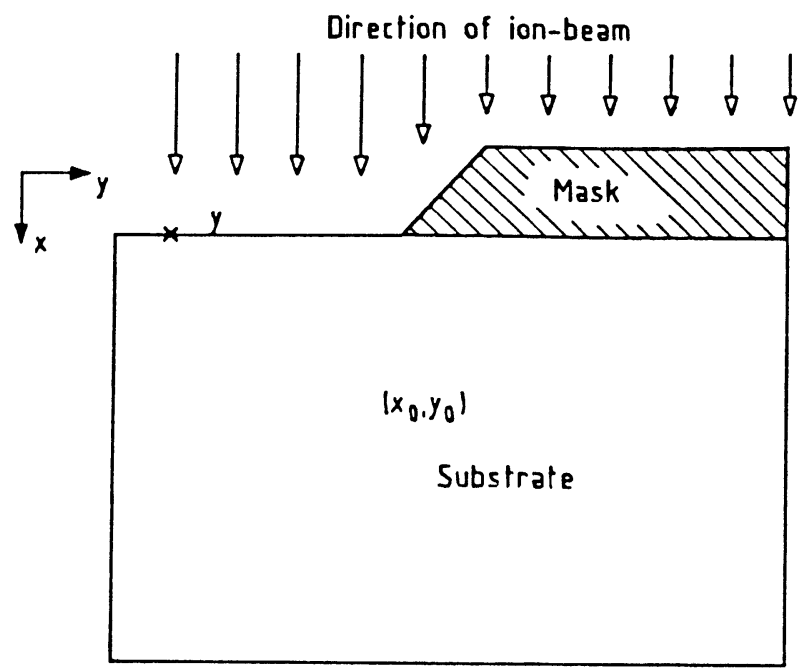

Fig. 1. - Silicon wafer geometry for modelling ionimplantation.

We assumed that an ion entering the target at a point $y$ will come to rest at a point $\left(x_{0}, y_{0}\right)$ with the probability density $P_{x}\left(x_{0}\right) P_{y}\left(y-y_{0}\right) . P_{x}$ is the probability density in the $x$-direction (vertical direction parallel to the direction of ion-beam) and $P_{y}$ is the probability density in the $y$-direction (lateral direction). According to Furukawa [6], the distribution $P_{y}$ of implanted ions is supposed to be a Gaussian function with a lateral deviation $\Delta R_{y}$. To simulate the vertical direction of the final resting points of ions, the simple Gaussian approximation is no longer valid: experiments have shown that profiles are skewed and possess tails. Three measured and tabulated lengths [7] characterized these profiles: the average projected range $R_{p}$, the standard deviation $\Delta R_{x}$ and the skewness $\gamma$. From these three parameters, two distributions are widely used : two joint half-Gaussian for arsenic, phosphorus and antimony [8] and a modified Pearson IV function for boron [9].

In the case of a vertical and infinitely high mask edge (resist for example), the impurity concentration is given by an analytical expression [10]. In a more general case of an arbitrarily shaped mask edge, it is assumed that the stopping power of the mask nearly equals the stopping power of silicon [11]. The mask is then considered as a silicon layer and the twodimensional profile is obtained numerically. The application presented in section IV gives a first example of boron implantation with a photoresist mask considered as a vertical mask edge, and a second one concerning arsenic implantation through a field oxide.
2.2 REDISTRIBUTION OF IMPURITIES. - The process of thermal diffusion of dopant impurities is an essential part of all semiconductor device fabrication. This effect is described by the well known diffusion equation $[12,13]$ :

$$
\begin{aligned}
\frac{\partial N_{k}}{\partial t}(x, y, t) & =\operatorname{div}\left[D _ { k } \left(\operatorname{grad} N_{k}-\right.\right. \\
& \left.\left.-Z_{k} \frac{\frac{N_{k}}{2 n_{i}}}{\left(\frac{M^{2}}{4 n_{i}^{2}}+1\right)^{1 / 2}} \operatorname{grad} M\right)\right]
\end{aligned}
$$

where

$N_{k}$ is the concentration of the $k$-th impurity, $D_{k}$ is the effective diffusion coefficient of the $k$-th impurity,

$Z_{k}=1$ for acceptor-like impurities, $=-1$ for donor-like impurities,

$n_{i}$ is the intrinsic carrier concentration in the semiconductor, and

$$
M=\sum_{k} Z_{k} N_{k}
$$

This relation is based on the assumption of a complete impurities ionization. The effective diffusion coefficient for boron, arsenic and antimony can be written as [9] :

$$
D_{k}=D_{k}^{0} \cdot \frac{1+\beta_{k} f_{k}}{1+\beta_{k}}
$$

where $D_{k}^{0}$ is the intrinsic diffusion coefficient of the $k$-th impurity, $\boldsymbol{\beta}_{k}$ is a phenomenological coefficient equal to 19 for boron, 100 for arsenic and 1 for antimony ; $f_{k}=p / n_{i}$ or $n / n_{i}$ for acceptor-like or donor-like impurities, respectively, or phosphorus, the well known model of Fair and Tsai [14] is used.

The non-linear diffusion equation must be solved

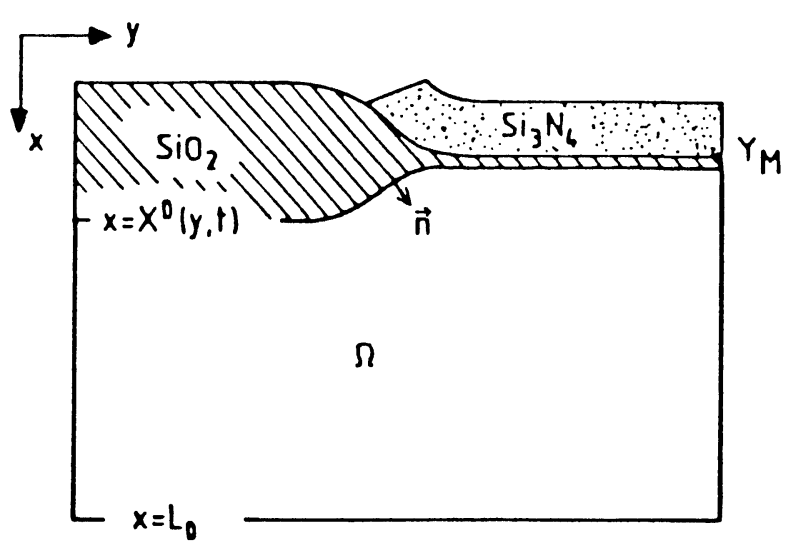

Fig. 2. - Physical domain $\Omega$ used to solve the diffusion equation. 
for the silicon wafer geometry shown in figure 2 . The physical domain $\Omega$ is described by :

$$
\left\{\begin{array}{l}
X^{0}(y, t) \leqq x \leqq L_{0} \\
0 \leqq y \leqq Y_{M}
\end{array}\right.
$$

where $L_{0}$ is the useful silicon layer thickness and $X^{0}(y, t)$ is the equation for the position of the silicon/oxide interface. In the case of redistribution in an oxidizing ambient the domain $\Omega$ varies with time. It is assumed to be symmetric, or large enough in the $y$-direction. So the boundary conditions are given as follows :

\section{- Conditions of symmetry:}

$$
\left.\begin{array}{c|c}
\left.\frac{\partial N_{k}}{\partial y}\right|_{y}=0 \\
\left.\frac{\partial N_{k}}{\partial y}\right|_{y}=0 \\
=Y_{M}
\end{array}\right\} X^{0}(y, t) \leqq x \leqq L_{0} .
$$

- Assumption of sufficiently deep domain :

$$
\left.\frac{\partial N_{k}}{\partial x}\right|_{x=L_{0}}=0 \quad 0 \leqq y \leqq Y_{M} .
$$

The boundary condition at oxide/silicon interface is written by assuming that there is no diffusion into the oxide and that, at all times, the segregation corresponds to equilibrium; so that :

$$
\begin{aligned}
\left(k_{s}-m\right) & N_{k} \mathbf{v}_{\mathrm{SiO}_{2}} \cdot \mathbf{n}= \\
= & D_{k}\left(\frac{\partial N_{k}}{\partial n}-Z_{k} \frac{\frac{N_{k}}{2 n_{i}}}{\sqrt{\frac{M^{2}}{4 n_{i}^{2}}}+1} \frac{\partial M}{\partial n}\right)
\end{aligned}
$$

where

$k_{s}$ is the segregation coefficient of the $k$ impurity at the oxide/silicon interface,

$m$ is the fractional total oxide growth due to the consumption of silicon,

$\mathbf{v}_{\mathrm{SiO}_{2}}$ is the oxide growth rate,

$\mathbf{n}$ is the unit normal vector to the $\mathrm{SiO}_{2} / \mathrm{Si}$ interface.

Then, the physical domain $\Omega$ is mapped into a fixed-time invariant rectangular domain by means of a coordinate transformation [1].

Next, the classical method of finite differences [15] and a Crank-Nicolson scheme [16] are used to a discretize the so obtained partial differential equations. The numerical solution is performed using the Gauss-Seidel method. The strong nonlinearity of the problem does not allow a method of overrelaxation to be used.

Using all these methods we have developed the program OSIRIS of reduced size and reasonable CPU time [10].

\section{Simulation of the field oxide growth.}

Selective oxidation provides a simple way of isolation of integrated circuits on silicon. In the LOCOS process, a nitride layer deposited on a pad-oxide is used as an oxidation mask : this process is known to give rise to a « bird's beak », due to lateral oxidation under the mask [17].

An accurate simulation of this effect is necessary in order to ensure a better control of the technological oxidation process. Solving the complete set of physical differential equations governing the oxide growth and the simultaneous viscous flow, one can obtain quite good results but it is difficult and computer-time consuming [18-20]. Therefore, in this section, we present semirecessed oxide shapes obtained by using simple parametric relationship based on the analysis of experimental data $[17,21,22]$.

First, as is shown in figure 3 , two shapes of the «bird's beak» can be experimentally observed, depending on the stress exerted by the mask. In the

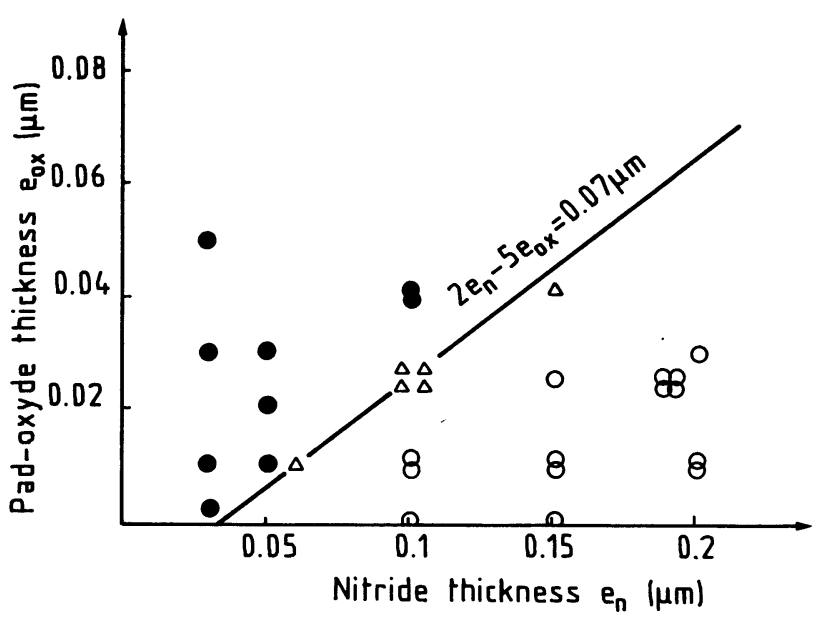

Fig. 3. - Classification of the bird's beak shapes observed experimentally $\bullet$ shape $1, \quad \bigcirc$ shape $2, \wedge$ unclassified shape.

case of the shape 1 (Fig. $4 \mathrm{a}$ ), the nitride layer and the pad-oxide thickness, $e_{n}$ and $e_{0 \dot{x}}$ respectively, are thin, resulting in a low mask stress. In the case of shape 2 (Fig. 4b), the nitride layer is thick, resulting in a large mask stress.

Two analytical functions $Z_{1}$ and $Z_{2}$ are thus needed to fit the contours at the oxide/silicon interface and at the oxide/ambient or nitride interface. Two complementary-error functions are used for shape 1 :

$$
\begin{aligned}
& Z_{1}(y)=a_{1} \operatorname{erfc}\left(b_{1} y+c_{1}\right)+d_{1} \\
& Z_{2}(y)=a_{2} \operatorname{erfc}\left(b_{2} y+c_{2}\right)+d_{2} .
\end{aligned}
$$

For shape 2, because of the strong mask stress, a pinch of the oxide appears under the nitride edge, for the upper interface, and shifted back a length $\delta$, 


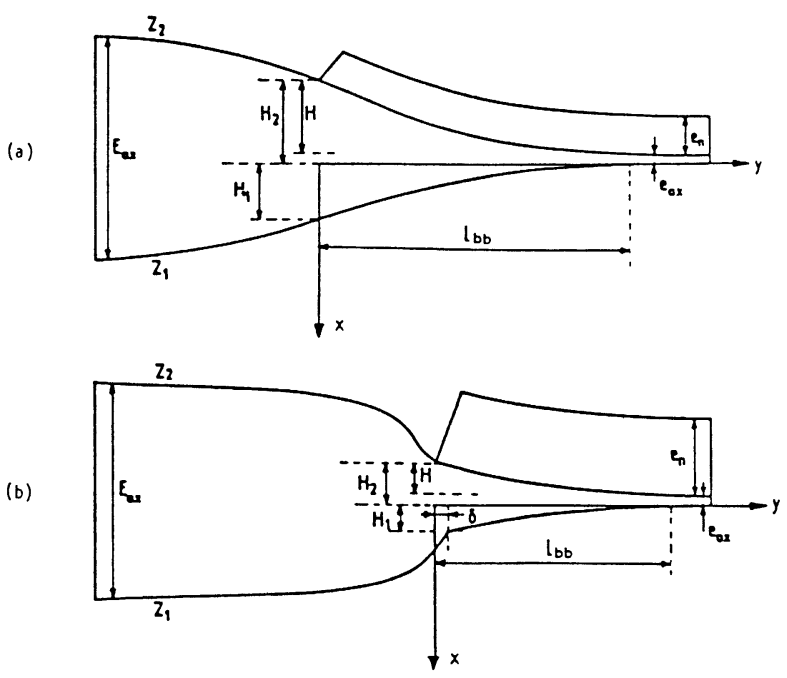

Fig. 4. - The two shapes of the bird's beak with characteristic lengths $\left(E_{0 x}, L_{\mathrm{bb}}\right.$ and $\left.H\right)$ and processing parameters $\left(e_{0 x}\right.$ and $\left.e_{n}\right):$ a) shape $\left.1, \mathrm{~b}\right)$ shape 2 .

at the oxide/silicon interface. Therefore, two different functions are used to simulate the «bird's beak " contours on the left side and on the right side of this pinch :

$$
\begin{array}{ll}
Z_{1}(y)=a_{i} \operatorname{erfc}\left(b_{1}^{\prime}(y-\delta)\right)+c_{1}^{\prime} \text { for } y \geqq \delta \\
Z_{1}(y)=e_{i} \frac{d_{1}^{\prime}-y}{d_{1}^{\prime}-y+q}
\end{array} \begin{aligned}
& \text { for } y \leqq \delta \\
& Z_{2}(y)=a_{2}^{\prime} \operatorname{erfc}\left(b_{2}^{\prime} y\right)+c_{2}^{\prime} \text { for } y \geqq 0 \\
& Z_{2}(y)=e_{2}^{\prime} \frac{d_{2}^{\prime}-y}{d_{2}^{\prime}-y+q} \text { for } y \leqq 0
\end{aligned}
$$

where $q=0.05 \mu$ and $\delta=0.04 \mu \mathrm{m}$.

The values of the two parameters $q$ and $\delta$ have been determined experimentally: $\delta$ can be easily measured on the field oxide shapes obtained using SEM technique; $q$ is chosen equal to $0.05 \mu \mathrm{m}$ in order to obtain the best fitting of the observed field oxide shape with the function :

$$
\frac{d_{2}^{\prime}-y}{d_{2}^{\prime}-y+q} \text {. }
$$

The parameters $a_{1}, b_{1}, a_{1}^{\prime}, b_{1}^{\prime}, \ldots$ are functions of processing parameters $e_{0 x}$ and $e_{n}$, and three characteristic features of the « bird's beak »: $E_{0 x}$ (given by Deal Grove's model [23]), $L_{\mathrm{bb}}$ (Length of lateral oxidation under the nitride layer) and $H$ (lifting of the mask during oxidation) $[21,24,25]$. At the beginning of the oxidation cycle, we assumed that the initial pad-oxide was etched on the left side of the mask edge so :

$$
\begin{aligned}
& \left.\begin{array}{l}
Z_{1}(y)=0 \\
Z_{2}(y)=0
\end{array}\right\} \quad y \leqq 0 \\
& \left.\begin{array}{l}
Z_{1}(y)=0 \\
Z_{2}(y)=-e_{0 x}
\end{array}\right\} \quad y \geqq 0 .
\end{aligned}
$$

Besides, the following assumptions are made :

1) There is no oxidation under the mask, far from the nitride edge. So that :

$$
\left.\begin{array}{l}
Z_{1}(y)=0 \\
Z_{2}(y)=-e_{0 x}
\end{array}\right\} \text { for } y \rightarrow+\infty
$$

2) In the field region and far from the nitride edge, the oxide thickness $E_{0 x}$ is given by Deal and Grove's model :

$$
\left.\begin{array}{l}
Z_{1}(y)=m E_{0 x} \\
Z_{2}(y)=(m-1) E_{0 x}
\end{array}\right\} \text { for } y \rightarrow-\infty
$$

where $m$ is the fractional total oxide growth due to the consumption of silicon.

3) The thickness of silicon consumed under the mask is given by $H_{1}=\frac{m}{1-m} H$, where $H$ is the lifting of the nitride mask during oxidation

$$
\begin{aligned}
& Z_{1}(0)=H_{1} \\
& Z_{2}(0)=-H-e_{0 x}=-H_{2} .
\end{aligned}
$$

4) The length of lateral oxidation under the mask, $L_{\mathrm{bb}}$, is measured between the edge of the nitride and the point where the slope of the oxide contour can be neglected compared to the slope at the origin. So that :

$$
\begin{aligned}
& \left.\frac{\partial Z_{1}}{\partial y}\right|_{y=L_{\mathrm{bb}}}=\left.\varepsilon \frac{\partial Z_{1}}{\partial y}\right|_{y=0} \\
& \left.\frac{\partial Z_{2}}{\partial y}\right|_{y=L_{\mathrm{bb}}}=\left.\varepsilon \frac{\partial Z_{2}}{\partial y}\right|_{y=0}
\end{aligned}
$$

with $\varepsilon=10 \%$.

Assuming these 4 conditions, the field oxide contours are described as follows.

Shape 1:

$$
Z_{1}(y)=a_{1} \operatorname{erfc}\left(b_{1} y+c_{1}\right)
$$

where

$$
\begin{aligned}
& a_{1}= \frac{m}{2} E_{0 x} \\
& b_{1}= \frac{-c_{1}+\sqrt{E+c_{1}^{2}}}{L_{\mathrm{bb}}}(E=-\log \varepsilon) \\
& c_{1}= \frac{\sqrt{\pi}}{2}\left[1-\frac{H_{1}}{a_{1}}\right] \\
& Z_{2}(y)=a_{2} \operatorname{erfc}\left(b_{2} y+c_{2}\right)+d_{2}
\end{aligned}
$$

where

$$
\begin{aligned}
& a_{2}=\frac{(m-1) E_{0 x}+e_{0 x}}{2} \\
& b_{2}=\frac{-c_{2}+\sqrt{E+c_{2}^{2}}}{L_{\mathrm{bb}}} \\
& c_{2}=\frac{\sqrt{\pi}}{2}\left[1-\frac{H_{2}}{a_{2}}\right] \\
& d_{2}=-e_{0 x} .
\end{aligned}
$$


Shape 2:

$$
Z_{1}(y)=a_{1}^{\prime} \operatorname{erfc}\left[b_{1}^{\prime}(y-\delta)\right] \text { for } y \geqq \delta
$$

where

$$
\begin{gathered}
a_{1}^{\prime}=H_{1} \\
b_{1}^{\prime}=\frac{\sqrt{E}}{L_{\mathrm{bb}}} \\
Z_{1}(y)=e_{1}^{\prime} \frac{d_{1}^{\prime}-y}{d_{1}^{\prime}-y+q} \quad \text { for } y \leqq \delta
\end{gathered}
$$

where

$$
\begin{gathered}
d_{1}^{\prime}=\delta-\frac{H_{1} q}{H_{1}-e_{1}^{\prime}} \\
e_{1}^{\prime}=m E_{0 x} \\
Z_{2}(y)=a_{2}^{\prime} \operatorname{erfc}\left(b_{2}^{\prime} y\right)+c_{2}^{\prime} \text { for } y \geqq 0
\end{gathered}
$$

where

$$
\begin{gathered}
a_{2}^{\prime}=-H \\
b_{2}^{\prime}=\frac{\sqrt{E}}{L_{\mathrm{bb}}} \\
c_{2}^{\prime}=-e_{0 x} \\
Z_{2}(y)=e_{2}^{\prime} \frac{d_{2}^{\prime}-y}{d_{2}^{\prime}-y+q} \text { for } y \leqq 0
\end{gathered}
$$

where

$$
\begin{aligned}
& d_{2}^{\prime}=\frac{-H_{2} q}{H_{2}+e_{2}^{\prime}} \\
& e_{2}^{\prime}=(m-1) e_{0 x}
\end{aligned}
$$

$E_{0 x}$ is given by Deal and Grove's model [23], $L_{\mathrm{bb}}$ and $H$ are plotted in figures 5-9 and can be described by :

$$
\begin{aligned}
& \begin{aligned}
L_{\mathrm{bb}}=K_{L}\left[\left(-T_{0 x}\right.\right. & +1580.3) E_{0 x}^{0.67} \times \\
& \left.\times \exp \left[-\frac{\left(e_{n}-0.08\right)^{2}}{0.06}\right] e_{0 x}^{0.3}\right]
\end{aligned} \\
& H=K_{H}\left(\left(-1.75 e_{n}+0.445\right) E_{0 x} \exp \left(-\frac{T_{0 x}}{200}\right)\right)
\end{aligned}
$$

where $T_{0 x}$ is the absolute temperature, $K_{L}=$ $8.25 \times 10^{-3} K_{H}=402.00$, and $E_{0 x}, e_{0 x}$ and $e_{n}$ are measured in $\mu \mathrm{m}$.

Within the range of interest :

$$
\begin{aligned}
& 0.1 \mu \mathrm{m} \leqq E_{0 x} \leqq 1.5 \mu \mathrm{m}, \\
& 850{ }^{\circ} \mathrm{C} \leqq T_{0 x} \leqq 1100{ }^{\circ} \mathrm{C}, \\
& 0.05 \mu \mathrm{m} \leqq e_{n} \leqq 0.2 \mu \mathrm{m}, \\
& \text { native oxide } \leqq e_{0 x} \leqq 0.05 \mu \mathrm{m}, \\
& \langle 100\rangle \text { substrate } .
\end{aligned}
$$

Hereafter, we compare the shape of the «bird's beak » obtained by Secondary Electron Microscopy

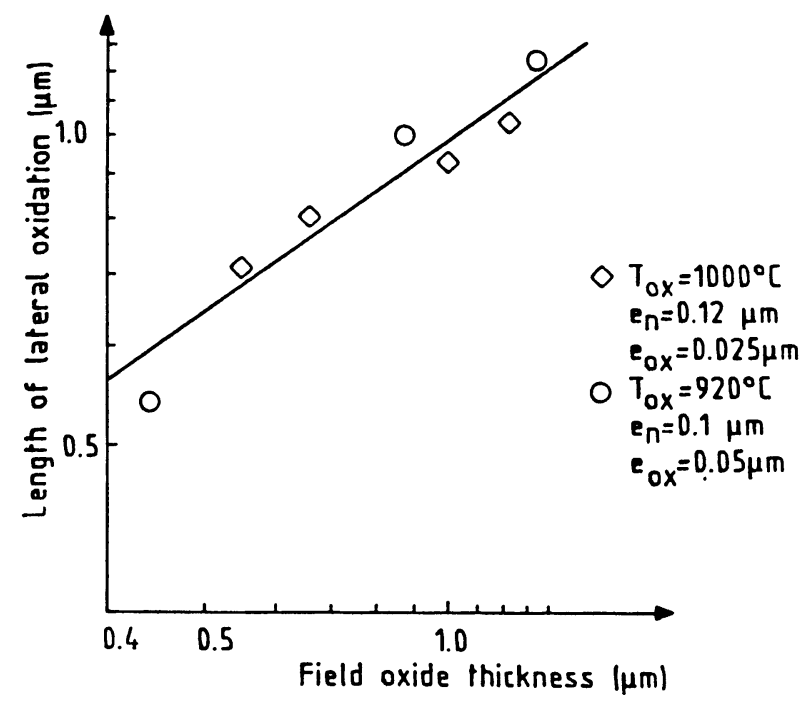

Fig. 5. - Length $L_{\mathrm{bb}}$ of lateral oxidation under the mask for the bird's beak versus field oxide thickness $E_{0 x}$.

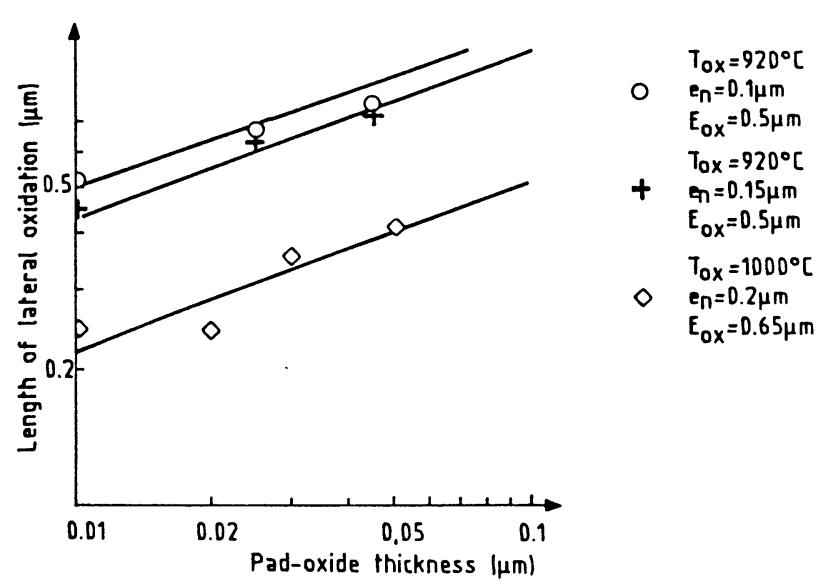

Fig. 6. - Length $L_{\mathrm{bb}}$ of lateral oxidation under the mask versus pad-oxide thickness $e_{0 x}$.

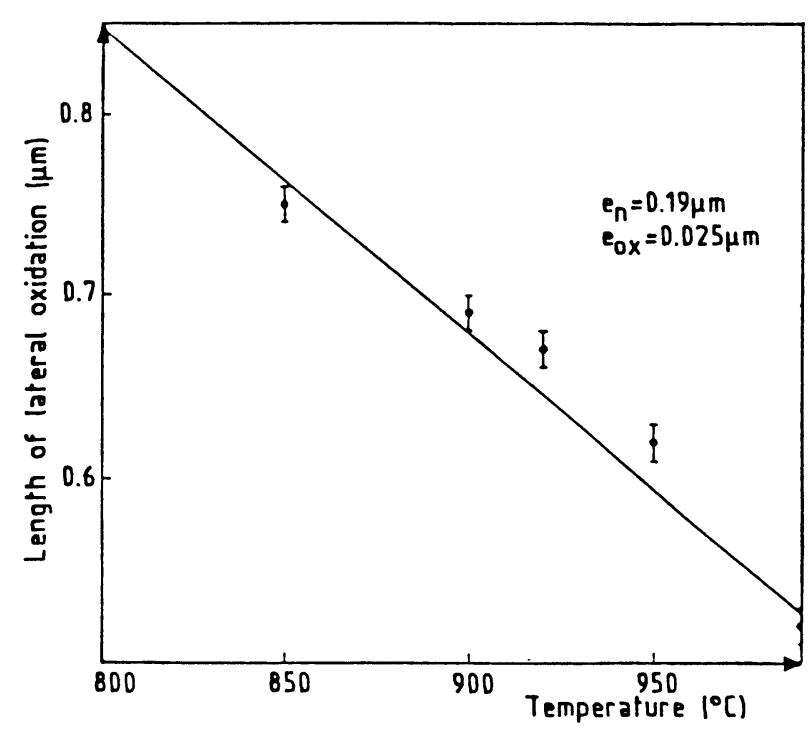

Fig. 7. - Length $L_{\mathrm{bb}}$ of lateral oxidation under the mask versus processing temperature $T_{0 x}$. 


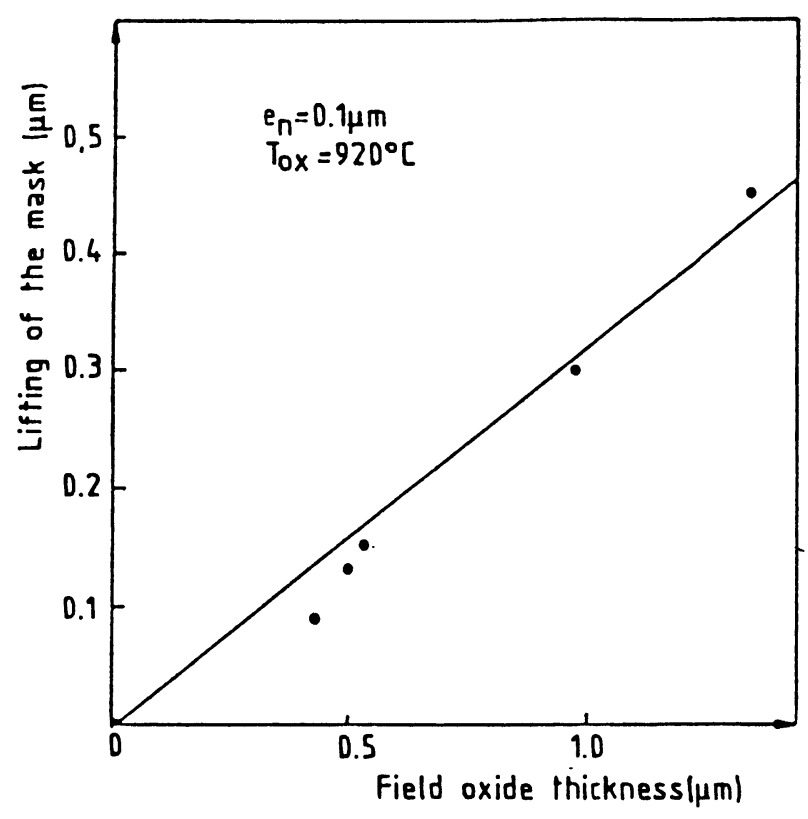

Fig. 8. - Lifting $H$ of the mask during oxidation for the bird's beak versus oxide thickness $E_{0 x}$.

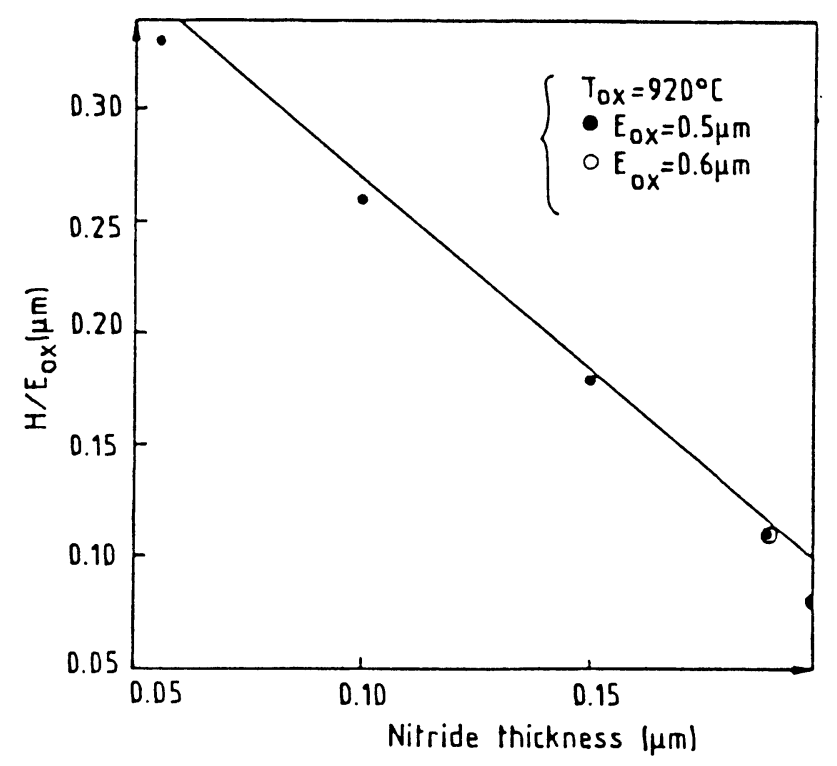

Fig. 9. $-H / E_{0 x}$ versus nitride thickness $e_{n}$.

(SEM) with simulated profiles. A good agreement between experimental data and analytical results can be observed in figure 10 .

\section{Simulation of a N-Channel MOS device.}

As an example, OSIRIS is used to simulate the entire processing sequence for the $\mathrm{N}$-Channel MOS device in figure 11 . The process schedule is the following :
- Field implant with boron $(120 \mathrm{keV}$, $10^{13} \mathrm{~cm}^{-2}$ ).

- Field oxidation $\left(950^{\circ} \mathrm{C}, 300 \mathrm{~min}\right)$.

- Gate oxidation up to $0.05 \mu \mathrm{m}$.

- Depletion implant with arsenic $(180 \mathrm{keV}$, $2 \times 10^{11} \mathrm{~cm}^{-2}$ ).

- Enhancement implant with boron $(40 \mathrm{keV}$, $2 \times 10^{11} \mathrm{~cm}^{-2}$ ).

- Dry argon anneal $\left(900^{\circ} \mathrm{C}, 30 \mathrm{~min}\right)$.

- Source-drain implant with arsenic $(120 \mathrm{keV}$, $10^{15} \mathrm{~cm}^{-2}$ ).

- Reflow process $\left(850^{\circ} \mathrm{C}, 30 \mathrm{~min}\right)$.

- Contacts.

The process employes six different mask operations and uses a local oxidation of silicon (LOCOS) scheme for isolation. For simulation, the device is divided into 5 main parts. The surface topographies and corresponding equi-density contours for impurity concentrations, at the end of the process, are given in figure 12 .

\section{Conclusion.}

We have developed a complete two-dimensional simulator of technological processes OSIRIS. The most important process steps for MOS devices such as predeposition, ion-implantation, oxide growth and thermal redistribution of doping impurities can be simulated.

The modelling of ion-implantation is performed using a Gaussian function for the lateral distribution while two empirical functions are used for the vertical ion-distribution : a joint half-Gaussian function for arsenic, phosphorus and antimony and a modified Person IV function for boron. Concerning the field oxide growth, a new analytical model has been developed, allowing a very good simulation of the "bird's beak » which appears in the LOCOS process. The diffusion for one or two impurities is described by solving the non-linear system of diffusion equations. OSIRIS uses the finite differences method with a Crank-Nicolson scheme. The system so-obtained is solved using a modified Gauss-Seidel method. The redistribution of impurities can be simulated in an inert or oxidizing ambient: the physical domain of the device is always mapped into a fixed-time invariant rectangular domain by means of a coordinate transformation.

Finally, OSIRIS is used to simulate a complete NChannel MOS device. The redistributed impurity profiles for this latter application are presented along with the corresponding oxide layer shapes at the end of the process. 


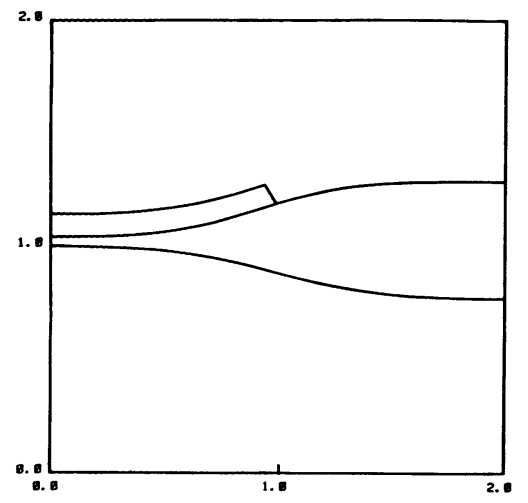

Semirecessed oxide

(SEMIROX)

Shape 1

$\mathrm{T}_{\mathrm{OX}}=920^{\circ} \mathrm{C}$

$E_{0 X}=0.52 \mu \mathrm{m}$

$e_{n}=0.1 \mu \mathrm{m}$

$e_{0 x}=0.04 \mu \mathrm{m}$

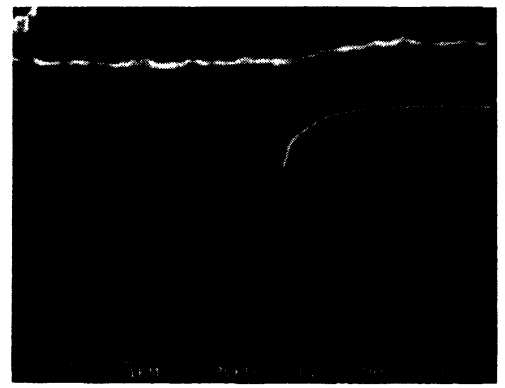

Semirecessed oxide [SEMIROX)

Shape 2

$\mathrm{T}_{\mathrm{OX}}=920^{\circ} \mathrm{C}$

$E_{0 x}=0.65 \mu \mathrm{m}$ $e_{n}=0.19 \mu \mathrm{m}$ $e_{0 x}=0.01 \mu \mathrm{m}$
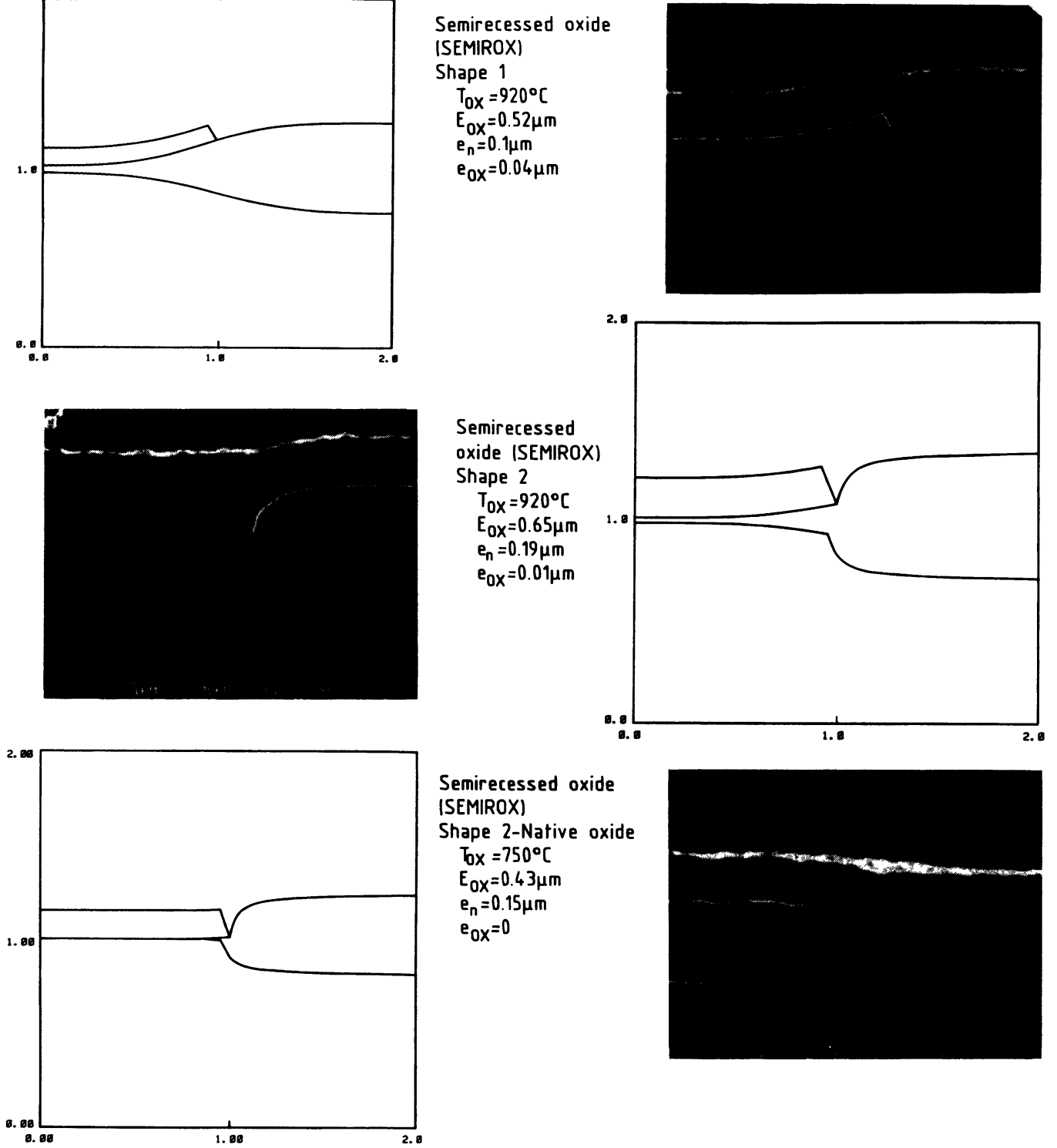

Semirecessed oxide (SEMIROX)

Shape 2-Native oxide $\mathrm{bx}=750^{\circ} \mathrm{C}$ $\mathrm{E}_{0 \mathrm{x}}=0.43 \mu \mathrm{m}$ $e_{n}=0.15 \mu \mathrm{m}$ $\mathrm{e}_{\mathrm{OX}}=0$

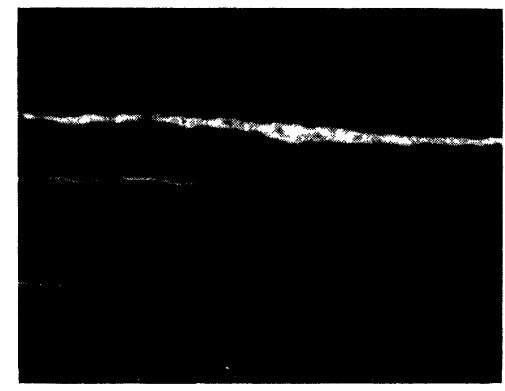

Fig. 10. - Comparison between experimental and simulated field oxide shapes.

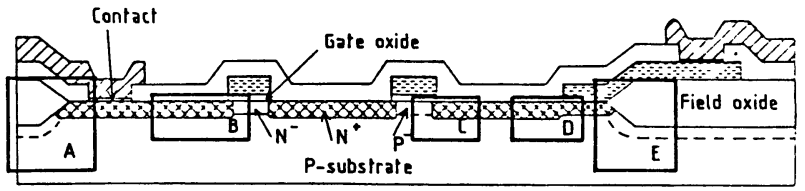

Fig. 11. - Cross sectional view of an N-Channel MOS device. The parts A-E of the circuit are simulated in figure 12 . 

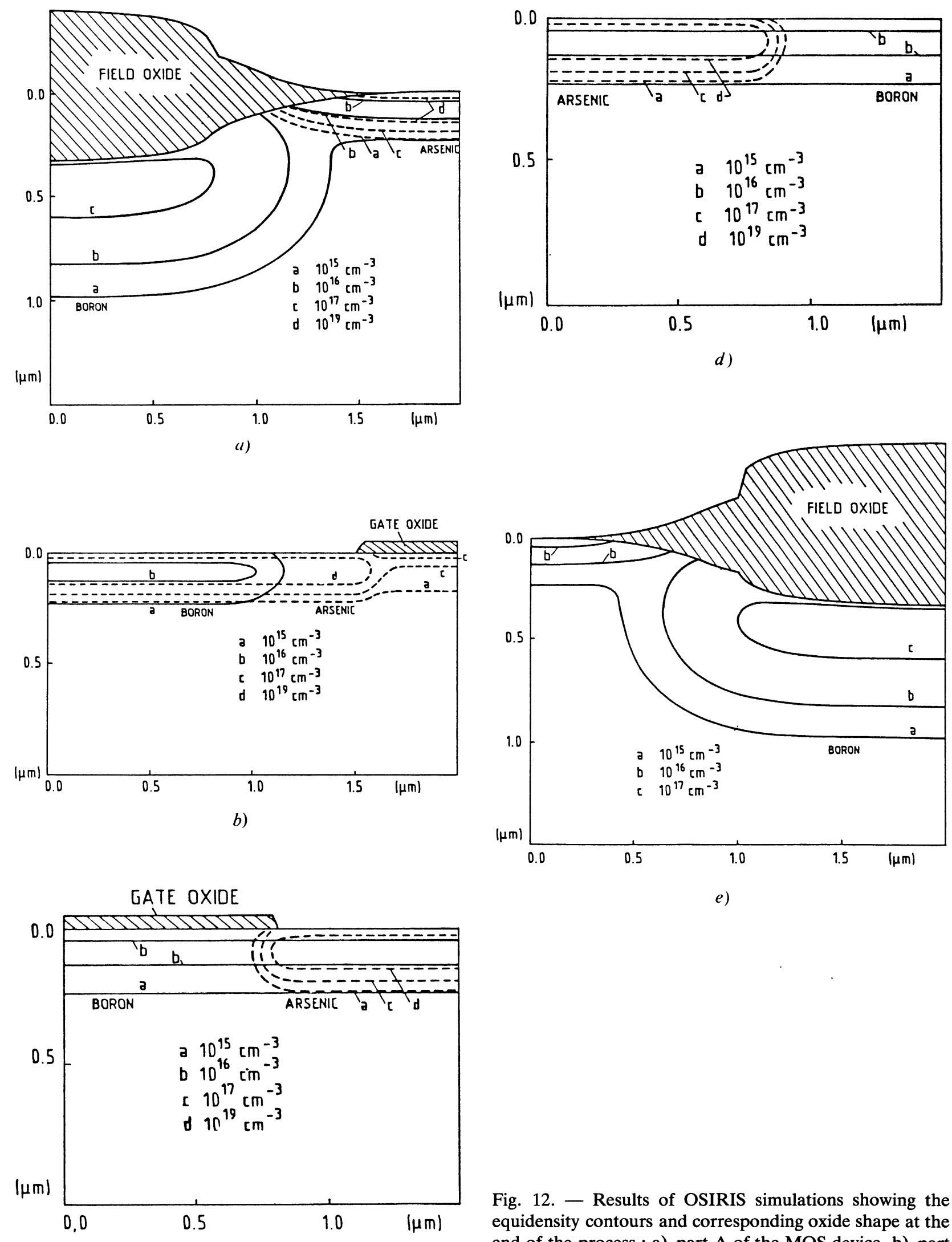

e)

Fig. 12. - Results of OSIRIS simulations showing the equidensity contours and corresponding oxide shape at the end of the process : a) part A of the MOS device, b) part $B$, c) part $C$, d) part $D$, e) part $E$. 


\section{References}

[1] Maldonado, C. D., ROMANS II, a two-dimensional process simulator for modelling and simulation in the design of VLSI devices, Appl. Phys. A 31 (1983) 119-138.

[2] Tielert, R., Two-dimensional numerical simulation of impurity redistribution in VLSI processes, IEEE Trans. ED 27 (1980) 1479-1483.

[3] Salsburg, K. A. and Hansen, H. H., FEDSS, Finite-Element Diffusion-Simulation System, IEEE Trans. ED 30 (1983) 1004-1011.

[4] Guillemot, N., Chenevier, P., DerouxDAuphin, P. and Gonchond, J. P., Présentation et validation du programme OSIRIS de simulation bidimensionnelle des processus technologiques, Revue Phys. Appl. 19 (1984) 987995.

[5] Guillemot, N. and Pananakakis, G., OSIRISOutil pour la Simulation de la Redistribution des Impuretés dans le Silicium, Solid-State Electron. 28 (1985) I-III.

[6] Furukawa, S., Matsumura, H. and Ishiwara, H., Theoretical considerations on lateral spread of implanted ions, Jpn J. Appl. Phys. 11 (1972) 134-142.

[7] Gibbons, J. F., Johnson, W. S. and Mylroie, S. W., Projected Range Statistics, Stroudsburg, PA (Dowdon, Hutchison and Ross) 1975.

[8] Gibbons, J. F. and Mylroie, S., Estimation of impurity profiles in ion-implanted amorphous target using joined half-Gaussian distributions, Appl. Phys. Lett. 22 (1973) 568-569.

[9] Antoniadis, D. A., Hansen, S. E. and Dutton, R. W., Suprem II, a Program for IC Process Modelling and Simulation, Stanford Univ., Stanford, CA. Tech. Rep., June 1978.

[10] Guillemot, N., Simulation bidimensionnelle des processus technologiques du silicium, élaboration du programme OSIRIS. Thèse I.N.P. Grenoble, 1986.

[11] Runge, H., Distribution of implanted ions under arbitrarily shaped mask edges, Phys. Status Solidi (A) 39 (1977) 595-599.

[12] NuYTs, W. and Van Overstraten, R., Computer calculation of impurity profiles in silicon (I), Phys. Status Solidi (A) 15 (1973) 329-341.
[13] Nuyts, W. and Van Overstraten, R., Computer calculation of impurity profiles in silicon (II), Phys. Status Solidi (A) 15 (1973) 445-472.

[14] FAIR, R. B. and TsAI, J. C. C., A quantitative model for the diffusion of phosphorus in silicon and the emitter dip effect, J. Electrochem. Soc. 124 (1977) 1107-1117.

[15] FoRsYTHE and WASOW, Finite Difference Methods for Partial Differential Equations (John Wiley and Sons inc.) 1960.

[16] Crank, J., Nicolson, P., A practical method for numerical evolution of solutions of partial differential equations fort heat-conduction type, Proc. Cambridge Philos. Soc. 43 (1947) 50-67.

[17] Deroux, P., Etude et optimisation du procédé LOCOS, application aux structures MOS VLSI. Thèse USM, Grenoble 1984.

[18] Matsumuto, H. and Fukuma, M., Numerical modelling of nonuniform $\mathrm{Si}$ thermal oxidation, IEEE Trans. ED 32 (1985) 132-140.

[19] CHIN, D. et al., Two-dimensional oxidation, IEEE Trans. ED 30 (1983) 744-749.

[20] CHIN, D. et al., A general solution method for twodimensional non-planar oxidation, IEEE Trans. ED 30 (1983) 993-998.

[21] Guillemot, N. and Pananakakis, G., Improvement of the two-dimensional process simulator OSIRIS, Proc. of MIEL'85 conf., Ljubljana, Yugoslavia (1985) 307-314.

[22] Bassous, E., Yu, H. N. and Maniscalo, V., Topology of silicon structures with recessed $\mathrm{SiO}_{2}$, J. Electrochem. Soc. 123 (1976) 1729-1737.

[23] Deal, B. E. and Grove, A. S., General relationship for the thermal oxidation in silicon, J. Appl. Phys. 36 (1965).

[24] Wu, T. C., Stacy, W. T. and Ritz, K. N., The influence of the LOCOS processing parameters on the shape of the bird's beak structure, $J$. Electrochem. Soc. 130 (1983) 1563-1566.

[25] Shankoff, T. A. et al., Bird's beak configuration and elimination of gate oxide thinning produced during selective oxidation, J. Electrochem. Soc. 127 (1980) 216-222. 